\title{
Maltrato Psicológico a los Niños, Niñas y Adolescentes en la Familia: Definición y Valoración de su Gravedad
}

\section{Child Psychological Maltreatment in the Family: Definition and Severity Assessment}

\author{
$\mathrm{M}^{\mathrm{a}}$ Ignacia Arruabarrena \\ Universidad del País Vasco, Spain
}

\begin{abstract}
Resumen. El maltrato psicológico a los niños, niñas y adolescentes en la familia es una de las tipologías principales y potencialmente más dañinas de desprotección infantil y a la vez una de las que presenta mayores dificultades para su identificación, evaluación y abordaje. Sin embargo, la atención que ha recibido por parte de investigadores y profesionales y responsables de los Servicios de Protección Infantil ha sido limitada, en comparación con otras tipologías como el abuso sexual, el maltrato físico e incluso la negligencia. Uno de los primeros problemas que aparecen al revisar el conocimiento disponible sobre el maltrato psicológico es la dificultad para su definición. En este artículo se presenta una revisión al respecto, junto con una revisión de algunos instrumentos diseñados para valorar su gravedad. Éstos han servido de base para la elaboración en la Comunidad Autónoma Vasca (España) de criterios más específicos que los hasta ahora disponibles en los servicios de infancia en España para la valoración de la existencia y gravedad del maltrato psicológico. El artículo presenta dichos criterios.

Palabras clave: definición, gravedad, maltrato psicológico infantil, valoración.
\end{abstract}

\begin{abstract}
Psychological maltreatment is one of the main and potentially more destructive forms of child maltreatment. It is difficult to identify, assess and treat. Compared to other forms of child maltreatment such as sexual abuse, physical abuse and neglect, attention received from researchers, child protection service managers and practitioners has been scarce. A review of available knowledge about psychological maltreatment reveals challenges to define the concept in ways useful to policy makers and practitioners. This paper presents a review of definitions of child psychological maltreatment and several measures available for assessing its severity. The review has been used in the Comunidad Autónoma Vasca (Spain) to develop more specific criteria for the identification and severity assessment of child psychological maltreatment in Spanish children services. This paper develops these criteria.

Keywords: definition, child psychological maltreatment, severity.
\end{abstract}

Está fuera de toda duda que el establecimiento de unos vínculos afectivos seguros y estables y la satisfacción de las necesidades emocionales básicas del niño ${ }^{1}$ son condiciones imprescindibles para asegurar su bienestar y permitirle un desarrollo sano. Está también fuera de toda duda la importancia de la familia y particularmente de las figuras parentales en este cometido. Pero las relaciones familiares, y las relaciones padreshijos en particular, incluyen aun siendo positivas un cierto grado de ambivalencia, conflicto y dificultades. Muchos profesionales que desarrollan su actividad con niños, niñas y adolescentes -no sólo en los Servicios Sociales, sino también en los ámbitos de la salud mental o educativo por ejemplo-, tratan con familias en las que identifican comportamientos parentales o pautas de relación padres-hijos que consideran dañinas o no beneficiosas para el bienestar emocional de los niños, recomendando diferentes estrategias de intervención

Correspondencia: $\mathrm{M}^{\mathrm{a}}$ Ignacia Arruabarrena. Departamento de Psicología Social y Metodología de las Ciencias del Comportamiento. Facultad de Psicología. Avda. Tolosa, 70. 20018 San Sebastián, Spain. E-mail: ignacia.arruabarrena@ehu.es para corregirlos. Cuando el componente principal del comportamiento parental que se considera dañino para el niño es de carácter psicológico, no es infrecuente que los profesionales que atienden estos casos los califiquen como maltrato o abandono psicológico/emocional. Pero ¿se quiere decir lo mismo cuando se utilizan estos términos?, ¿disponemos de criterios suficientemente precisos y comunes para determinar cuándo un comportamiento parental debe ser considerado maltrato?, ¿disponemos de herramientas o instrumentos válidos para su identificación y valoración?

Poco aportan en este sentido los criterios que el DSM-IV-TR y la CIE-10 proporcionan a los profesionales de la salud mental para el diagnóstico del maltrato psicológico infantil. El DSM-IV-TR (American Psychiatric Association, 2002) hace referencia en la categoría de Problemas de relación a los Problemas paterno-filiales (Z63.8), señalando que "esta categoría debe usarse cuando el objeto de atención clínica es el patrón de relación entre padres e hijos (p.ej., deterioro de la comunicación, sobreprotección, disciplina inadecuada) que está asociado a un deterioro clínicamente significativo de la actividad individual o familiar o la 
aparición de síntomas clínicamente significativos en los padres o hijos" (p. 823). En el epígrafe Problemas relacionados con el abuso o la negligencia, el DSMIV-TR se refiere al abuso físico (T74.1), al abuso sexual (T74.2) o a la negligencia (T74.0) hacia el niño, pero no incluye el maltrato o abuso psicológico. Por su parte, la CIE-10 (Organización Mundial de la Salud, 2001) incluye en Otros procesos frecuentemente asociados con trastornos mentales y del comportamiento situaciones como Patrones de relaciones familiares alterados en la infancia (Z61.2), Hechos conducentes a la pérdida de la autoestima en la niñez (Z61.3), Experiencias personales atemorizantes en la niñez (Z61.7), Sobreprotección parental (Z62.1), Hostigamiento y acusación de culpabilidad al niño (Z62.3), Abandono emocional del niño (Z62.4), y Presiones inapropiadas de los padres y otras anormalidades en la crianza (Z62.6). Sin embargo, la CIE-10 no proporciona criterios para el diagnóstico de este tipo de situaciones.

Diversas organizaciones y asociaciones profesionales han elaborado su propia definición del maltrato psicológico. Éste figura de forma invariable en todas las clasificaciones sobre la desprotección infantil -es decir, sobre las diferentes situaciones de maltrato que pueden producirse hacia los niños en el seno familiarque se han propuesto hasta la fecha. A él le acompañan como tipologías principales el maltrato físico, la negligencia y el abuso sexual, además de otras tipologías que varían según sistemas clasificatorios.

La Asociación Internacional para la Prevención del Abuso y Negligencia Infantil define el maltrato psicológico como "el fracaso en proporcionar al niño un entorno evolutivamente apropiado y de apoyo, incluyendo la disponibilidad de una figura primaria de apego, de forma que pueda desarrollar un conjunto estable y completo de competencias emocionales y sociales que corresponden con sus potencialidades personales en el contexto de la sociedad en la que vive. Puede consistir también en actos hacia el niño que le provocan o tienen una alta probabilidad de provocarle daño en su salud o en su desarrollo físico, mental, espiritual, moral o social. Estos actos deben estar razonablemente bajo el control de los padres o personas que mantengan con él una relación de responsabilidad, confianza o poder. Los actos incluyen restricción del movimiento, patrones de rechazo, denigración, culpabilización, amenazas, inducción de miedo, discriminación, ridiculización u otras formas no físicas de tratamiento hostil o rechazante" (International Society for Prevention of Child Abuse and Neglect, 1999). Por su parte, la Asociación Profesional Americana sobre el Abuso Infantil define el maltrato psicológico como "un patrón repetido o un incidente/s extremo/s de rechazo, aterrorizar, aislamiento, explotación/corrupción, ignorar y/o negligencia hacia la salud mental/médica/educativa del niño. Tales conductas transmiten al niño el mensaje de ser inútil, defectuoso, no querido, estar en peligro, o sólo valioso en la medida en que satisface las necesidades de otro" (American Professional Society on the Abuse of Children, 1995). Si bien estas definiciones gozan de una amplia aceptación, profesionales e investigadores necesitan definiciones más operativas y precisas, y es aquí donde se presentan las dificultades (Brassard y Donovan, 2006). Tal y como hoy día afirman Baker y Festinger (2011), "ningún escrito que trata sobre el maltrato psicológico puede escapar al comentario de la falta de consenso sobre su definición" (p. 69).

Éste es uno de los problemas que limita de forma importante los hallazgos de la investigación y la validez de los datos actualmente disponibles sobre la incidencia y prevalencia real del fenómeno. Algunos estudios llevados a cabo en España indican que el maltrato psicológico puede encontrarse presente como tipología única o asociada en un $25-45 \%$ de los casos de desprotección atendidos por los Servicios de Protección Infantil y que constituye la segunda tipología más frecuente después de la negligencia (Federación de Asociaciones para la Prevención del Maltrato Infantil, 2010; Palacios, 1995). Sin embargo, estos datos deben ser tomados con cautela dadas las diferencias metodológicas de los estudios de los que provienen y que incluyen, entre otros, diferencias en la clasificación y definición de las distintas tipologías de desprotección, en las fuentes de información consultadas, y en la forma en que se computa la concurrencia de tipologías. Problemas similares se encuentra la Asociación Internacional para la Prevención del Abuso y Negligencia Infantil, que tras recoger los datos aportados por informantes de 75 países, concluye en la imposibilidad de disponer de cifras fiables respecto a la prevalencia de las distintas tipologías de desprotección. Las diferencias en su definición y en el grado de precisión y fiabilidad de los sistemas de registro de la información entre los diferentes países - e incluso dentro del mismo país entre diferentes regiones o comunidades- impiden conocer cuántos casos se están produciendo, a qué tipologías corresponden, y si el fenómeno se está incrementando o disminuyendo (International Society for Prevention of Child Abuse and Neglect, 2008).

Las investigaciones realizadas sobre la incidencia y prevalencia de la desprotección infantil han mostrado con claridad que una parte muy importante de los casos que se producen no llegan a conocimiento de los Servicios de Protección Infantil (Euser, van Ijzendoorn, Prinzie y Bakermans-Kranenburg, 2010), por lo que los estudios realizados con población general pueden reflejar mejor las dimensiones reales del problema. En el caso del maltrato psicológico, la revisión de Binggeli, Hart y Brassard (2001) sitúa en torno al 30\% el porcentaje de la población general que refiere haber sido víctima de maltrato psicológico en su infancia, mientras que Hart, Brassard, Binggeli y Davidson 
(2002) sitúan este porcentaje entre el 10 y el $15 \%$ al considerar el maltrato psicológico en sus formas más severas y crónicas. Es posible que estos datos se acerquen más a las dimensiones reales del problema que las estadísticas de los Servicios de Protección Infantil, pero en cualquier caso han de ser tomadas con cautela entre otras razones porque parece existir entre la población general una tendencia a minimizar la importancia de este tipo de experiencias en la propia infancia (Brassard y Donovan, 2006) y a responder de forma diferente en función de si las preguntas formuladas son de carácter general o específico (Baker y Festinger, 2011).

El maltrato psicológico constituye una de las tipologías de desprotección infantil que mayores dificultades presenta para su identificación, evaluación y abordaje. Como se ha señalado previamente, parte de ellas derivan de los problemas inherentes a su propia definición. Incluso en la bibliografía especializada y profesional no hay consenso en su propia denominación; a él se han referido como emotional abuse, emotional neglect, emotional maltreatment, psychological abuse, psychological battering, o psychological maltreatment (Baker, 2009). En general, emotional abuse y psychological abuse se utilizan para referirse a actos hostiles hacia el niño, mientras que emotional neglect y psychological neglect lo hacen para referirse a omisiones. Los términos emotional maltreatment y psychological maltreatment son los de uso más generalizado; ambos incluyen tanto acciones como omisiones que implican desatención a las necesidades psicológicas del niño. En muchas ocasiones dichos términos se utilizan, equivocadamente como argumenta O'Hagan (1993), como sinónimos. En este texto se han seguido las recomendaciones de Baker (2009), Hart et al. (2002) y McGee y Wolfe (1991) de utilizar la denominación psychological maltreatment (traducida como maltrato psicológico) por ser más amplia y permitir incluir componentes tanto afectivos como cognitivos.

El maltrato psicológico ha sido, de las cuatro tipologías principales de desprotección -maltrato físico, negligencia, abuso sexual y maltrato psicológico-, una de las últimas en recibir la atención de investigadores y de los propios Servicios de Protección Infantil. Según Brassard y Donovan (2006), las razones de ello pueden ser varias: la minimización de su importancia dada su elevada frecuencia, la consideración de que un cierto grado de agresión psicológica en la familia es normal y esperable, o el carácter en general no físico de sus secuelas, que hace que profesionales y responsables de la administración pública sientan una menor urgencia y presión para intervenir que en los casos de maltrato físico, abuso sexual o negligencia física severa. Revisiones recientes muestran la preponderancia del interés sobre el abuso sexual frente a otras tipologías como el maltrato físico o la negligencia en publicaciones e investigaciones del ámbito de la psicología y la salud mental
(Chaffin, 2006). En la misma línea se encuentra la revisión de las publicaciones realizadas en Child Maltreatment, una de las revistas especializadas de mayor calidad sobre el tema, que muestra que entre los años 1996 y 2010 el número de artículos publicados sobre maltrato psicológico fue sensiblemente inferior al de artículos sobre abuso sexual, maltrato físico y negligencia, que se situaron en primer, segundo y tercer lugar respectivamente (Feiring y Zielinski, 2011).

Muy frecuentemente el maltrato psicológico se presenta asociado a otras tipologías de desprotección (ver la revisión de Herrenkohl y Herrenkohl, 2009), aunque también lo hace de forma aislada. En cualquiera de los casos, las investigaciones apuntan que sus efectos en el desarrollo infantil pueden ser extremadamente negativos; numerosos estudios han identificado un amplio abanico de dificultades emocionales, comportamentales y cognitivas en los niños víctimas de maltrato psicológico que se mantienen en la adolescencia y madurez (ver las revisiones de Brassard y Donovan, 2006; Hart et al., 2002). Cuando se presenta de forma aisla$\mathrm{da}$, los estudios realizados sugieren que el maltrato psicológico está asociado a efectos de una severidad igual o mayor que las restantes tipologías de desprotección. Son de interés en este sentido los resultados del Minnesota Parent-Child Project, un estudio longitudinal realizado con 267 familias en situación de riesgo, donde se encontró que los niños víctima de negligencia emocional manifestaron, en comparación a los niños víctima de otras tipologías de desprotección, más problemas y dificultades en distintas áreas de desarrollo y a lo largo de diferentes momentos evolutivos (Erickson y Egeland, 2002). Por su parte, Hart et al. (2002) hacen referencia a investigaciones que sugieren que las secuelas más frecuentes y duraderas del maltrato físico, el abuso sexual y la negligencia tienden a estar relacionadas con las experiencias psicológicas asociadas. Esto mismo lo plantearon de forma rotunda Garbarino, Guttmann y Seeley en el primer libro publicado enteramente sobre el tema en el año 1986. En sus primeras páginas, los autores escriben: "más que relegar al maltrato psicológico como una cuestión secundaria, subordinada a otras formas de maltrato y negligencia, deberíamos situarlo como la pieza central en los esfuerzos por entender el funcionamiento familiar y proteger a los niños. En casi todos los casos, son las consecuencias psicológicas de un acto las que lo definen como maltratante" (p. 7), "el maltrato psicológico constituye el núcleo central del fenómeno más amplio de la desprotección infantil. Es su nexo unificador y el aspecto crítico en la abrumadora mayoría de los casos de maltrato físico y abuso sexual" (p. 8). En la misma línea se encuentran Hart et al. (2002) cuando afirman que "el maltrato psicológico puede ser visto como un concepto unificador que abarca gran parte de los componentes más significativos de la desprotección infantil" (p. 79). 


\section{Definición de maltrato psicológico}

\section{Cuestiones generales sobre la definición de la desprotección infantil}

Se ha escrito mucho sobre los parámetros en base a los cuales se ha de definir qué es la desprotección infantil y sus diferentes manifestaciones. En el continuo del comportamiento parental, implica establecer el límite entre un comportamiento parental inadecuado -esto es, que puede dañar al niño- pero tolerable, y un comportamiento parental inadecuado e intolerable, esto es, no permisible de acuerdo a las normas sociales establecidas en la legislación vigente. Son este último tipo de comportamientos los que se consideran desprotección infantil, un concepto administrativo-legal que varía en el tiempo y en el espacio y establece cuándo la sociedad, representada por la administración pública, no sólo puede sino que debe intervenir en la intimidad de una familia con el objeto de promover y/o preservar el bienestar y la protección de un niño. En los casos de mayor gravedad, tal intervención ha de llevarse a cabo aun con la oposición de los padres o responsables legales del niño y puede conllevar su separación temporal o permanente de su familia.

Si bien legislaciones de países desarrollados como Estados Unidos, Inglaterra, Canadá o Australia mencionan explícitamente al maltrato psicológico como tipología de desprotección, el caso de España no es así. El artículo 172.1 del Código Civil y el artículo 17 de la Ley Orgánica 1/1996, de 15 de enero, de Protección Jurídica del Menor se refieren a las situaciones de desprotección infantil como situaciones de riesgo y desamparo, definiéndolas de forma muy genérica. Lo mismo sucede con la mayor parte de legislaciones autonómicas en esta materia. De esta forma, los Servicios de Protección Infantil de nuestro país se han visto obligados, dentro de ese marco legal, a desarrollar definiciones más precisas acerca de qué es la desprotección infantil y sus diferentes manifestaciones. Más adelante volveremos a hacer referencia a esta cuestión.

Como muestra la revisión de Chalk (2006), hay un acuerdo generalizado en que la definición del concepto de desprotección infantil ha de descansar en dos elementos: el comportamiento del adulto y sus consecuencias en el niño. Nótese que el concepto de consecuencias asume la existencia de un nexo causal entre ambos elementos. Las situaciones de desprotección se definirían de esta forma como aquellas en que hay un comportamiento inadecuado de los adultos que ha provocado o potencialmente puede provocar un daño significativo en el niño. Tal comportamiento puede producirse de diferentes formas -por acción u omisión- y puede ser de índole físico o psicológico. En función de la tipología específica de la que se trate, el peso de cada uno de los dos componentes -comportamiento parental y daño en el niño- varía. Como puede observarse, la definición de desprotección no hace referen- cia a la intencionalidad del comportamiento parental.

Es importante tomar en consideración que la determinación de si existe desprotección no requiere que el comportamiento parental haya producido necesariamente un daño constatable en el menor (demonstrable harm) -sea a nivel físico, cognitivo, social o emocional-. La definición de desprotección incluye también (a) la consideración de que el comportamiento parental coloca al niño en peligro (endangerment) de sufrir un daño significativo aun cuando éste no se haya producido, y (b) situaciones en que el comportamiento parental es tan extremo, inherentemente traumático o inadecuado en su naturaleza que puede asumirse que se ha producido un daño emocional significativo, incluso aunque el niño pueda no mostrar signos obvios de daño ni a nivel físico ni comportamental (US Department of Health and Human Services, 2009).

\section{El concepto de daño significativo}

El concepto de daño significativo -real y potenciales central tanto en la definición de qué es desprotección infantil como en la valoración de su gravedad. Pero definir qué es daño (harm) y más específicamente daño significativo (significant harm) no parece fácil, especialmente cuando éste no es de carácter físico.

McGee y Wolfe presentaron en 1991 una revisión de lo que diferentes investigadores establecían en ese momento como daño psicológico:

- daño emocional serio (por ejemplo, retraimiento extremo, agresión o ansiedad);

- daño emocional serio manifestado en ansiedad severa, depresión, retraimiento, o agresión intensa hacia sí mismo o hacia otros;

- daño en la capacidad intelectual o psicológica del niño manifestada en una limitación observable y sustancial en su capacidad para funcionar en el nivel normal de rendimiento y conducta esperable en su contexto cultural; y

- diagnóstico de desviaciones en el desarrollo general, emocional o comportamental en grado suficiente como para resultar imprescindible una intervención para garantizar la seguridad y bienestar del niño.

El carácter general de estas definiciones vuelve a aparecer en la revisión más reciente de Baker (2009):

- limitación en el desarrollo de las competencias del niño;

- funcionamiento psicológico o desarrollo dañado;

- daño inmediato o a largo plazo en el funcionamiento comportamental, cognitivo, afectivo, social, psicológico o físico del niño;

- daño en la autoestima del niño, degradación de sus sentimientos de competencia y pertenencia, e impedimento de un desarrollo sano y vigoroso;

- daño psicológico y restricción a la superación por parte del niño de logros evolutivos importantes; y 
- daño o reducción sustancial de las capacidades potenciales del niño a nivel cognitivo, intelectual, perceptivo, lingüístico, en su memoria, atención y sentido moral.

El concepto de daño psicológico es recogido en la mayoría de leyes federales estadounidenses sobre desprotección infantil. Según la revisión realizada por la Child Welfare Information Gateway (2007), el término legal utilizado para referirse al daño psicológico es mental injury, definido como "daño a la capacidad psicológica o a la estabilidad emocional del niño evidenciada por un cambio observable o sustancial en su conducta, respuesta emocional o cognición" o "ansiedad, depresión, retraimiento o conducta agresiva".

Buscando criterios más objetivables y definiciones más específicas sobre el daño significativo se encuentra la propuesta de Little, Axford y Morpeth (2003). Estos autores proponen que la presencia o previsión de daño ha de ser evaluada en siete áreas: salud -compuesta por dos subáreas: salud física y psicológica- y desarrollo -compuesto por cinco subáreas: desarrollo físico, comportamental, intelectual/educativo, social y emocional-. De acuerdo a su propuesta, la presencia de daño significativo ha de determinarse cuando se dé alguna de las siguientes circunstancias:

1. El niño muestra un funcionamiento extremadamente limitado o disfuncional en una o varias áreas de desarrollo (incluye la manifestación de trastornos psicopatológicos severos, excluyendo los trastornos conductuales y emocionales más comunes).

2. El desarrollo del niño en una o varias áreas se encuentra en el extremo de lo esperable a su edad según las puntuaciones/estándares normativos.

3. El daño en una determinada área de desarrollo persiste y/o se agudiza a lo largo de diferentes etapas evolutivas.

4. El daño afecta simultáneamente a cuatro o más de las cinco áreas de desarrollo.

5. El niño muestra un nivel de daño en el desarrollo mayor que la mayoría de niños en situación similar a la suya.

En una línea semejante a la anterior se sitúa la Asociación Profesional Americana sobre el Abuso Infantil (American Professional Society on the Abuse of Children), que en el año 1995 publicó la guía, hoy vigente, Psychosocial evaluation of suspected psychological maltreatment in children and adolescents. En esta guía, el daño significativo en el desarrollo psicológico se define como la evidencia de una perturbación emocional severa de acuerdo a los criterios de la Education of All Handicapped Children Act (PL-94$142)^{2}$ o del DSM-IV, y la no consecución de los logros evolutivos esperables en una o más áreas de desarrollo, o su consecución en una forma seriamente distorsionada (la guía aporta, entre otros, un listado de los logros evolutivos fundamentales en las diferentes etapas de desarrollo hasta la madurez temprana).
Por último merece reseñarse la propuesta de Slep y Heyman (2006), que definen como impacto significativo a nivel psicológico:

1. Miedo (verbalizado o mostrado) de sufrir daño físico uno mismo u otras personas, y al menos uno de los siguientes síntomas de miedo o ansiedad durante como mínimo 24 horas: rememoración persistente e intrusiva del incidente (se incluye la que se evidencia en el juego); reacciones marcadas negativas a estímulos relacionados con el incidente, manifestadas en evitación de tales estímulos, malestar subjetivo o manifiesto hacia los mismos, o hiperactivación fisiológica ante ellos (nota: el perpetrador puede ser un estímulo); actuar o sentir como si el incidente fuera a repetirse; síntomas marcados de ansiedad como dificultad para conciliar o mantener el sueño, irritabilidad o explosiones de cólera, dificultad para concentrarse, hipervigilancia (p.ej., reacciones excesivamente sensibles a estímulos sonoros y visuales del entorno, vigilancia del entorno a la espera de un peligro, cambios bruscos de humor); respuesta exagerada de miedo.

2. Malestar psicológico significativo relacionado con el incidente: trastorno depresivo mayor, trastorno por estrés postraumático, trastorno agudo de estrés $\mathrm{u}$ otros trastornos psiquiátricos que cumplen los criterios diagnósticos del DSM-IV o están próximos a ello.

3. Síntomas somáticos de estrés (relacionados o exacerbados por el incidente) que interfieren de forma significativa el funcionamiento normal del niño (incluyen, pero no se limitan a dolores, migrañas, problemas gastrointestinales u otras enfermedades o malestares físicos relacionados con el estrés).

4. Disrupción/evolución negativa significativa en el desarrollo físico, psicológico, cognitivo o social del niño.

\section{Comportamientos parentales que pueden constituir maltrato psicológico}

Si la definición de qué constituye un daño psicológico significativo es difícil, la determinación de qué comportamientos concretos pueden constituir maltrato psicológico no lo es menos. Así lo mostró Gómez de Terreros (2006) en una de las escasas revisiones sobre el tema publicadas en nuestro país.

Glaser (2002) propone una serie de criterios para definir el maltrato psicológico que resultan de gran interés. Según esta autora, lo que define a esta tipología de desprotección es el tipo de relación paternofilial derivada del comportamiento parental. De acuerdo a su planteamiento, el maltrato psicológico: 
- describe una relación entre las figuras parentales y el niño (más que un evento o una serie de eventos repetidos que ocurren en el marco de la relación paterno-filial);

- los comportamientos parentales que conforman la interacción con el niño impregnan o caracterizan su relación actual -es decir, se producen siempre, habitualmente o a menudo y se observan en diferentes momentos y contextos-;

- los comportamientos parentales están provocando o potencialmente pueden provocar un daño en el desarrollo y salud psicológica/emocional del niño;

- incluye tanto omisión como comisión; y

- requiere que no haya contacto físico.

Asumiendo estas premisas, veamos cuáles son los aspectos específicos que han considerado los investigadores y expertos que se han propuesto definir de forma operativa el maltrato psicológico (American Professional Society on the Abuse of Children, 1995; Baker, 2009; Barnett, Manly y Cichetti, 1991; Brassard y Donovan, 2006; Glaser, 2002; Hart et al., 2002; McGee y Wolfe; 1991):

- Todas las definiciones asumen implícita o explícitamente que recibir unos cuidados psicológicos mínimamente adecuados en la infancia es una necesidad básica y universal para un desarrollo apropiado, en línea con los planteamientos teóricos y taxonómicos actuales sobre las necesidades humanas (Doyal y Gough, 1994) y las necesidades básicas en la infancia y adolescencia (López, 1995, 2008; UK Government, 2000).

- La definición de maltrato psicológico debe establecer criterios diferentes en función del estatus evolutivo del niño. Si bien la denominación de los tipos de situaciones incluidas en su definición puede ser válida de forma general, las conductas específicas que integran cada una de ellas pueden variar según el estatus evolutivo del niño.

- Ha habido debate sobre el peso que ha de asignarse en la definición de maltrato psicológico al comportamiento parental y a sus consecuencias en el niño. Se han elaborado definiciones diferentes en este sentido (para una completa revisión al respecto, véase Baker 2009). La discusión parece haberse decantado por la consideración de que la definición debe descansar en la evidencia de un comportamiento parental inadecuado más que en la constatación de daños significativos en el niño. Esta consideración parte del supuesto de que para calificar la existencia de maltrato psicológico es suficiente con la valoración de que el daño en el niño puede producirse tanto de forma inmediata como a medio o largo plazo. En este sentido, el daño que el comportamiento parental ya ha provocado en el niño debería ser tomado en consideración para valorar la gravedad del maltrato, pero no constituye un requisito para calificar su existencia.

- La definición del maltrato psicológico debe contemplar que el comportamiento parental puede tener un significado e impacto diferencial en el niño en función, entre otros, del contexto cultural en que se produce.

Una de las primeras y aún hoy en día más citadas propuestas de definición operativa del maltrato psicológico es la realizada por la Asociación Profesional Americana sobre el Abuso Infantil, que diferencia seis categorías o formas de maltrato psicológico:

1. Rechazar-rechazo/degradación hostil; incluye actos verbales y no verbales del adulto que rechazan y degradan al niño-.

2. Aterrorizar -amenazar al niño con sufrir un daño físico, morir, ser abandonado, o dejarle a él o a sus seres/objetos queridos en situaciones claramente peligrosas-.

3. Aislar -negar al niño de forma continuada oportunidades para satisfacer sus necesidades de interactuar/comunicarse con iguales o adultos dentro y fuera del entorno familiar-.

4. Explotación/corrupción -fomentar el desarrollo de conductas inapropiadas en el niño, por ejemplo, conductas autodestructivas, antisociales, delictivas, desviadas u otras conductas desadaptadas-.

5. Ignorar -ausencia de responsividad emocional; ignorar los intentos y necesidades del niño de interactuar -fracaso en expresarle afecto, protección y amor- y no mostrar emoción alguna en la interacción con él-.

6. Negligencia hacia la salud mental/médica/educativa -actos injustificados que ignoran, no permiten o fracasan en proporcionar el tratamiento requerido para los problemas o necesidades de salud mental, médicas o educativas del niño(American Professional Society on the Abuse of Children, 1995).

En el año 2006, Brassard y Donovan presentan una revisión exhaustiva y extraordinariamente detallada de los tipos de comportamiento parental que se han incluido en las diferentes definiciones de maltrato psicológico realizadas por los investigadores. En su análisis, comparan estas definiciones con la propuesta por la Asociación Profesional Americana sobre el Abuso Infantil en el año 1995 (ver Tabla 1). Concluyen que aunque las distintas definiciones utilizan denominaciones diferentes para las distintas categorías o formas del maltrato psicológico, su contenido es bastante similar. El mayor grado de acuerdo entre definiciones se encuentra en las conductas de despreciar, discriminar/segregar, humillar en público, colocar al niño en un entorno impredecible o caótico, amenazar al niño y/o a sus seres queridos, modelar o permitir conductas antisociales y evolutivamente inapropiadas, y no mostrar afecto, protección y amor. Las mayores diferencias entre las definiciones se encuentran en las categorías de colocar al niño en situaciones claramente peligrosas y negligencia en la salud mental/médica/educativa, que muchas de ellas no categorizan como maltrato psicológico sino como negligencia. 


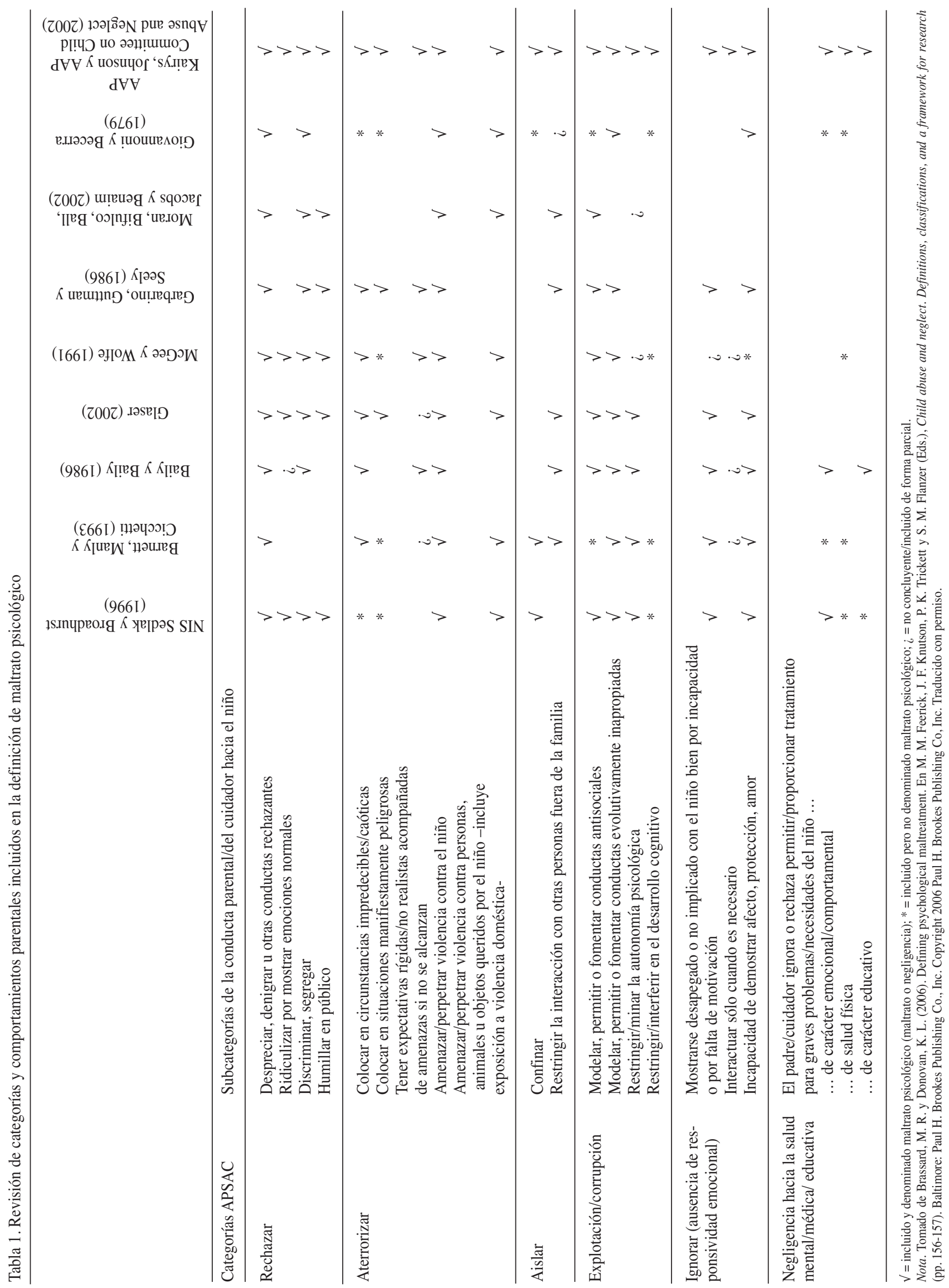


Brassard y Donovan (2006) presentan también una revisión de las investigaciones realizadas en relación al impacto en el niño de las cinco primeras formas de maltrato psicológico definidas por la Asociación Profesional Americana sobre el Abuso Infantil. Sus conclusiones indican que hay una fuerte evidencia empírica en relación al impacto negativo de las dos primeras (rechazar y aterrorizar), una fuerte evidencia empírica también en relación a la quinta forma de maltrato psicológico (ignorar) -especialmente cuando se produce a edades tempranas y el padre/madre maltratante es la única fuente de estimulación del niño-, y evidencias limitadas en relación al impacto de las formas de aislar y explotación/corrupción por la escasez de investigaciones al respecto.

Aún quedan muchas cuestiones pendientes en relación a la definición operativa del maltrato psicológico. Entre ellas se encuentra la inclusión o no de conductas propuestas en otras definiciones. Éste es el caso, por ejemplo, de la denominada desorientación cognitiva, propuesta por Moran y colaboradores como una forma extrema de tortura o secuestro psicológico que incluye "un conjunto de técnicas dirigidas a confundir y desorientar al niño en términos de: (a) su creencia en la evidencia de sus sentidos (por ejemplo, repetirle que ha entendido mal una orden que de hecho ha sido seguida de forma correcta), (b) su memoria (por ejemplo, instalar la creencia en el niño de que no puede recordar experiencias valiosas del pasado), o (c) su sentido de identidad (por ejemplo, convencer al niño de que su padre biológico no es tal o que un padre separado/divorciado ha muerto). En casos extremos se utilizan estrategias análogas al lavado de cerebro" (Moran, Bifulco, Ball, Jacobs y Benaim 2002; en Brassard y Donovan, 2006, p. 166). Otras definiciones incluyen como maltrato psicológico confundir la identidad sexual del niño (Baily y Baily, 1986; en Brassard y Donovan, 2006), realizar demandas contradictorias y ambivalentes (Kairys, Johnson y Committee on Child Abuse and Neglect, 2002), manifestar un estilo de comportamiento parental inconsistente (McGee y Wolfe, 1991), o no reconocer la individualidad y límites psicológicos del niño, definido por Glaser (2002) como la utilización del niño para la satisfacción de las necesidades psicológicas de los padres y la incapacidad para distinguir entre la realidad del niño y las creencias y deseos del adulto. Según esta última autora, este tipo de conductas no son infrecuentes en parejas en procesos altamente conflictivos de separación o divorcio.

Dos últimos puntos de reflexión antes de finalizar esta revisión sobre la definición de maltrato psicológico. El primero de ellos, planteado en 1991 por Jay Belsky cuestiona el excesivo énfasis que la definición de daño coloca en el efecto duradero, a largo plazo del comportamiento parental maltratante en el niño. Según este autor, esta perspectiva deja de lado la experiencia vital diaria del niño, las experiencias que le dañan en el presente pero que no tienen un efecto duradero a largo plazo, al menos discernible. Belsky se pregunta si el concepto de dolor o sufrimiento (pain) debe ser también incluido en la definición de maltrato psicológico además del de daño (harm). Quizás, como plantea, el maltrato psicológico deba ser definido en términos del dolor/sufrimiento inmediato que provoca en el niño además de su potencial de daño significativo más duradero. Ningún otro autor de los revisados incluye, al menos explícitamente, la diferenciación entre inmediate pain y enduring harm planteada por Belsky. Es en cualquier caso una cuestión de interés para la reflexión.

En segundo lugar, si bien puede afirmarse que a lo largo de los últimos treinta años se han realizado propuestas que suponen un gran avance en la definición del maltrato psicológico, siguen vigentes las palabras de Egeland en relación a que "el maltrato psicológico es un constructo complejo que nunca podrá llegar a ser definido en forma de conductas específicas que puedan ser computables. Es un constructo que sólo puede ser inferido de una síntesis de información de múltiples fuentes. (...) Sería mucho más simple tanto para el investigador como para el profesional si el maltrato psicológico pudiera ser definido en términos de comportamientos parentales específicos observables. Sin embargo, esto es irreal porque el significado de determinadas conductas parentales y su efecto en el niño dependen de su nivel de desarrollo, el contexto en el que tienen lugar y (...) la intención que se encuentra detrás de ellas así como la atribución o interpretación del niño de dichas conductas (...). Determinar el significado e intención de la conducta parental implica la interpretación clínica de información tanto cualitativa como cuantitativa obtenida de diferentes fuentes. Hinde (1976) señaló que la valoración subjetiva de una relación puede ser más importante que las conductas objetivas que observamos. Sostuvo que lo que una persona piensa acerca de una relación puede ser más importante que la interacción que ocurre en la realidad. (...) la definición ... debe incluir criterios basados en datos clínicos. (...) Definir y operacionalizar este constructo en términos de un conjunto de criterios debe incluir tanto los aspectos objetivos de las "comunicaciones" parentales como el significado subjetivo que revela intenciones y motivaciones" (Egeland, 1991, p. 40-41). El juicio clínico sería, según este autor, de especial relevancia.

\section{Valoración de la gravedad del maltrato psicológico}

Una revisión del tema permite observar que los criterios utilizados para determinar la gravedad del maltrato psicológico han sido: (a) su intensidad, frecuencia y duración, (b) el grado en que impregna o caracteriza la relación paterno-filial, (c) la cantidad de tipos de conducta maltratante que se han producido o se están produciendo, (d) la presencia de otros factores en la 
vida del niño que pueden amortiguar el efecto del maltrato psicológico (por ejemplo, ¿el padre/madre maltratante proporciona en otros momentos afecto o tiene una relación positiva con el niño?, ¿el niño tiene acceso regular a un adulto no maltratante que le ofrezca cuidados y protección?), (e) la relevancia del maltrato en función de la edad del niño, del período evolutivo en que se encuentra y el que le va a seguir, y (f) el grado en que el niño ha sufrido, está gestando o se prevé que va a sufrir un daño significativo en su desarrollo (American Professional Society on the Abuse of Children, 1995; Baker, 2009; Barnett et al., 1991; Brassard y Donovan, 2006; Glaser, 2002; Hart et al., 2002; McGee y Wolfe, 1991).

Investigadores y Servicios de Protección Infantil han desarrollado diferentes instrumentos con el objetivo de evaluar la existencia y/o gravedad de la desprotección infantil, incluyendo el maltrato psicológico (para una completa revisión ver Amaya-Jackson, Socolar, Hunter, Runyan y Colindres, 2000; Baker, 2009; Baker y Festinger, 2011; Dubowitz, 2006; Portwood, 2006; Runyan y English, 2006; Stowman y Donohue, 2005)

Los instrumentos más desarrollados han sido los autoinformes para adultos, niños y adolescentes, administrados bien en forma escrita o a través de entrevistas personales o telefónicas. Este tipo de instrumentos han pasado de incluir una sola pregunta -con dos únicas opciones de respuesta: sí/no- a recoger ítems más numerosos y específicos. En la actualidad, los autoinformes varían de forma importante en cuanto a la cantidad y el grado de especificidad de sus ítems, y el período de tiempo que abarcan (en algunos casos no se define, otros incluyen el ciclo vital completo y otros se refieren a los doce, seis o tres meses previos). Algunos instrumentos únicamente recaban información sobre si la conducta/situación recogida en cada ítem se ha presentado o no. En menor medida incluyen datos sobre su frecuencia, y aún menos sobre la edad de inicio o su gravedad.

Un segundo tipo de instrumentos son los que se podrían denominar de cumplimentación con información recogida a través de la observación directa y/o múltiples fuentes. En este caso, se trata de instrumentos que describen -de forma más o menos exhaustivalas diferentes situaciones o conductas que pueden constituir desprotección, de forma que el instrumento sirve para calificar el conjunto de la información obtenida sobre el caso. Algunos de estos instrumentos han sido elaborados por y para investigadores mientras que otros lo han sido para su utilización en los Servicios de Protección Infantil.

Es sobre todo en este segundo tipo de instrumentos -aunque también hay algún autoinforme- donde se pueden encontrar propuestas de categorización de niveles de gravedad del maltrato psicológico que vayan más allá de descripciones de carácter general. Aquéllos que incluyen propuestas de mayor interés son
Child Well-Being Scales - CWBS (Magura y Moses, 1986), Ontario Child Neglect Index - CNI (Trocmé, 1996), Modified Maltreatment Classification System MMCS (English y the LONGSCAN Investigators, 1997), Graded Care Profile Scale - GCP (Srivastava y Polnay, 1997), Family Assessment Form - FAF (Children's Bureau of Southern California, 1997), y Eligibility Spectrum (Ontario Association of Children's Aid Societies, 2006).

Salvo el último instrumento -el Eligibility Spectrum, elaborado para su aplicación en los Servicios de Protección Infantil y basado en gran medida en las Child Well-Being Scales- todos los demás gozan de algún apoyo empírico en relación a su fiabilidad y validez (Portwood, 2006; Runyan y English, 2006; Stowman y Donohue, 2005), aunque siguen siendo necesarias más investigaciones al respecto. El Modified Maltreatment Classification System (English y the LONGSCAN Investigators, 1997) es, de los señalados, el instrumento más comprehensivo, completo y con mayor apoyo empírico (ver publicaciones recogidas en el monográfico de la revista Child Abuse \& Neglect, 2005, vol. 29 y otras relacionadas en http://www.iprc.unc.edu/longscan).

Los instrumentos anteriormente señalados presentan diferencias en algunos aspectos como:

1. El tipo de conductas/situaciones que incluyen como maltrato psicológico. Las situaciones de negligencia emocional y negligencia educativa son dos de las que más diferencias presentan; en algunos casos son incluidas en la tipología de maltrato psicológico, en otros en la tipología de negligencia, y en otros casos son definidas como tipologías independientes.

2. El intervalo del continuo del comportamiento parental que abarcan. Algunos de estos instrumentos recogen dicho continuo de forma completa, es decir, desde el comportamiento parental adecuado hasta el extremadamente dañino (es decir, los casos de maltrato más graves). Otros instrumentos inician su gradación a partir de comportamientos parentales con un cierto grado de inadecuación.

3. El número y denominación de los distintos niveles de gravedad que establecen y el significado de tal denominación. En general, los instrumentos diferencian entre tres y cinco niveles de gravedad. La denominación de los mismos es diferente, aunque es frecuente la utilización de las calificaciones de leve, moderado, grave y muy grave.

Los instrumentos difieren en la dotación de significado a los niveles de gravedad que establecen, por lo que distintos instrumentos pueden situar a las mismas o similares conductas/situaciones en diferentes niveles de gravedad. Incluso en el mismo instrumento, como el Modified Maltreatment Classification System, los propios 
autores advierten que la numeración de las distintas tipologías no implica idéntico nivel de gravedad (es decir, la calificación 5 en la tipología de maltrato psicológico no implica el mismo nivel de gravedad que esa misma calificación en otra tipología). Algunos instrumentos no asignan significado a los niveles de gravedad; éstos son exclusivamente graduados y numerados a lo largo de un continuo.

4. El grado de especificidad con el que describen las conductas/situaciones incluidas en cada nivel de gravedad.

5. Algunos de los instrumentos hacen referencia explícita a la necesidad de considerar otra información además de la recogida en relación al tipo de comportamiento parental y sus consecuencias reales o potenciales en el niño para valorar la gravedad. El Eligibility Spectrum, por ejemplo, se refiere de forma genérica a la edad del niño, sus capacidades intelectuales, su nivel de salud física y emocional general y su estatus evolutivo, la conducta del niño que puede afectar a su propia salud y seguridad, y su capacidad para acceder a factores protectores (circunstancias o personas) que pueden reducir el riesgo de sufrir un daño significativo. Por su parte, el Modified Maltreatment Classification System hace referencia a la cronicidad de la desprotección y a la edad del niño en el momento de su inicio.

\section{Definición y criterios para valorar la gravedad del maltrato psicológico en los Servicios de Protección Infantil en España: Situación actual y propuestas}

Las definiciones recogidas en los manuales de actuación de los Servicios de Protección Infantil de diferentes Comunidades Autónomas (Ayuntamiento de Madrid, 2008; Diputación Foral de Álava, 2004; Diputación Foral de Bizkaia, 2005; Diputación Foral de Gipuzkoa, 2003; Gobierno de Cantabria, 2006; Gobierno de Navarra, 2003; Gobierno del Principado de Asturias, 2008; Junta de Castilla y León, 1995) coinciden en varios aspectos: (a) diferencian las tipologías de maltrato emocional y abandono emocional, (b) recogen cinco de las seis formas de maltrato psicológico propuestas en el año 1995 por la Asociación Profesional Americana sobre el Abuso Infantil -rechazar, aterrorizar, aislar, ignorar y negligencia hacia la salud mental-, incluyendo las formas de explotación/corrupción y negligencia hacia la salud médica/educativa en otras tipologías, (c) incorporan como maltrato emocional las formas de sobreprotección, exposición a situaciones de violencia de pareja e instrumentalización en conflictos de pareja, y (d) definen criterios muy generales para valorar la existencia de daño significativo y para el establecimiento de la gravedad del maltrato psicológico.
La necesidad de utilizar el conocimiento disponible y avanzar en la línea de una mayor precisión tanto en la definición como en los criterios para valorar la gravedad de las situaciones de maltrato psicológico es, de acuerdo a lo anterior, evidente. Éste fue el objetivo de un trabajo desarrollado durante los años 2007 a 2010 en la Comunidad Autónoma Vasca, promovido por el Departamento de Empleo y Servicios Sociales del Gobierno Vasco. En él participaron profesionales de los Servicios de Protección Infantil e investigadores. $\mathrm{Su}$ resultado es el Instrumento Balora para la valoración de la gravedad de las situaciones de riesgo y desamparo (documento no publicado).

Las escalas referidas al maltrato psicológico que se incluyen en este instrumento fueron elaboradas tras una revisión, estudio y adaptación de los criterios e instrumentos descritos en apartados previos de este artículo. Las propuestas recogidas en relación al maltrato psicológico incluyen:

1. La diferenciación del maltrato psicológico por omisión y por acción. Así, el instrumento distingue las tipologías de Negligencia hacia necesidades psíquicas -definida como la desatención a las necesidades de interacción y afecto, estimulación y guía y orientación del niño, y el rechazo o retraso en la provisión de atención psicológica o psiquiátrica a problemas emocionales graves en éste- y Maltrato psíquico -definido como situaciones en que el niño ha sufrido un daño psíquico grave o hay riesgo de que lo sufra como consecuencia de las acciones de sus padres, incluyendo en algunos casos las acciones de otras personas que forman parte de la unidad convivencial-. La tipología de Negligencia hacia necesidades psíquicas incluye cuatro escalas (a) necesidades de interacción y afecto, (b) necesidades de estimulación, (c) atención específica a problemas emocionales graves y (d) necesidades de normas, límites y transmisión de valores morales positivos. La tipología de Maltrato psíquico incluye también cuatro escalas (a) maltrato emocional, (b) instrumentalización en conflictos entre las figuras parentales, (c) exposición a situaciones de violencia de pareja o entre miembros de la unidad convivencial, y (d) amenazas de agresión física. El instrumento define la Corrupción como tipología independiente.

2. La Negligencia hacia necesidades psíquicas y el Maltrato psíquico no se definen en base a incidentes aislados -aunque se contempla que pueda calificarse ante incidentes de alto contenido traumático- sino como un patrón reiterado o continuado de conductas negativas o de interacciones destructivas de los adultos hacia el niño.

3. El instrumento diferencia cuatro niveles de gravedad para cada escala: Muy elevada, Elevada, Moderada y Riesgo leve. Los tres primeros niveles de gravedad incluyen situaciones de despro- 
tección que requerirían la intervención de los Servicios de Protección Infantil: los Servicios Sociales Especializados en los dos primeros casos y los Servicios Sociales Municipales en el tercer caso. Las situaciones incluidas en el cuarto nivel de gravedad (riesgo leve) no constituyen situaciones de desprotección, aunque sí requerirían una intervención de carácter preventivo por incluir déficits leves en la atención al niño, esto es, pautas educativas o de trato hacia el niño que son inadecuadas y que aunque no le han provocado un daño significativo, si se mantienen podrían provocárselo en el futuro.

4. Los niveles de gravedad se establecen en base a la consideración combinada de cuatro elementos: (a) la intensidad y frecuencia del comportamiento del adulto, (b) la edad del niño, (c) la gravedad de las secuelas observables en éste y su previsible evolución, y (d) el riesgo potencial de que tales secuelas aparezcan en un futuro próximo. Además, determinadas escalas toman también en consideración para valorar la gravedad la existencia de figuras alternativas en el entorno del niño que compensen los déficits manifestados por las figuras parentales.

5. El instrumento define el daño psíquico significativo como aquellas situaciones en que el daño que sufre el niño en una o varias áreas de desarrollo (emocional, social y/o cognitivo) le coloca en los extremos de lo esperable a su edad o manifiesta un funcionamiento extremadamente limitado o perturbado; las dificultades en una o varias áreas de desarrollo persisten a lo largo de diferentes etapas evolutivas; o el daño afecta simultáneamente al menos a dos áreas de desarrollo (emocional, social y/o cognitivo).

Por su parte, se define daño psíquico grave como la presencia constatada en el niño, niña o adolescente de (a) un trastorno psicopatológico, (b) síntomas clínicos de ansiedad, depresión, retraimiento o conducta rechazante, conductas agresivas o autodestructivas, o retrasos en el desarrollo, o (c) otros problemas severos de comportamiento que comprometen seriamente su proceso de desarrollo y adaptación personal y social y requieren tratamiento especializado inmediato. El instrumento advierte sobre la dificultad de establecer un nexo causal entre los síntomas de daño psíquico que presenta un niño y el trato que recibe por parte de sus figuras parentales. Señala que en la mayoría de los casos dicho nexo únicamente puede establecerse en forma de hipótesis o estimaciones de probabilidad, raramente como certezas absolutas. El instrumento orienta a que cuando sean formuladas, dichas hipótesis o estimaciones sean debidamente argumentadas y se basen en el conocimiento actualmente disponible sobre las consecuencias del maltrato psicológico en el desarrollo infantil y adolescente. Se plantean los mismos criterios cuando se formulen predicciones de futuro en relación al daño potencial que una determinada situación puede producir en el desarrollo y bienestar del niño.

El instrumento también advierte que la ausencia de síntomas observables de daño psíquico en un niño cuyos padres tienen un comportamiento seriamente inadecuado no significa necesariamente ausencia de daño. El daño puede estar produciéndose y manifestarse en forma de síntomas agudos en momentos posteriores o valorarse que, aunque la situación puede no estar provocando un daño significativo en el momento actual, es probable que se produzca en un futuro próximo si la situación no se corrige.

6. El instrumento establece que la presencia y gravedad del daño psíquico debe ser evaluada por profesionales de la psicología o psiquiatría a través de la metodología e instrumentos propios de su disciplina profesional. Orienta a que cuando se utilicen pruebas autoaplicadas, se seleccionen aquellas que dispongan de índices adecuados de fiabilidad y validez. Recomienda que cuando se utilicen pruebas que no reúnan estas condiciones, nunca sean utilizadas como criterio único de valoración o diagnóstico y sus resultados sean interpretados con la debida precaución.

En el Apéndice I se presentan las escalas del instrumento Balora para la valoración de la gravedad de las tipologías de Negligencia hacia necesidades psíquicas y Maltrato psíquico.

\section{Comentarios finales}

El maltrato psicológico hacia los niños en la familia puede tener efectos altamente negativos para su bienestar y para su proceso de desarrollo. Incluso hay autores que plantean que, salvo los casos extremos de carácter físico o los que afectan a niños de corta edad, lo que realmente resulta dañino para el niño en las restantes situaciones de desprotección -maltrato físico, abuso sexual, negligencia física- es el componente de maltrato psicológico que les acompaña (Garbarino et al., 1986). A pesar de su relevancia, la revisión anterior ha puesto en evidencia la coincidencia de investigadores y profesionales en la extrema dificultad de definir, identificar y valorar este tipo de situaciones.

En los últimos treinta años se han producido avances significativos en este objetivo. En este artículo se han recogido las aportaciones consideradas más relevantes. Estas han servido de base para una propuesta de criterios que puedan ser utilizados por los profesionales de los Servicios de Protección Infantil y de la salud mental de nuestro país.

Obviamente, la disposición de estos criterios no resta complejidad a esa tarea ni resuelve todos los pro- 
blemas que puedan presentarse al valorar este tipo de casos. Aquí debe mencionarse, por ejemplo, la dificultad de establecer una relación causal entre el comportamiento parental y los síntomas de daño que puedan observarse en un determinado niño, o de realizar predicciones fiables respecto al daño potencial que tal comportamiento puede provocar en un niño concreto a corto, medio o largo plazo. Numerosas investigaciones han constatado que no existe una relación directa, inevitable y específica entre el comportamiento parental que puede ser definido como maltratante/negligente y la presencia de daño -actual o potencial- en el niño. Tal y como recogen Pearce y Pezzot-Pearce (1997) en su modelo transaccional del impacto de la desprotección infantil, hay otros factores además del comportamiento parental que influyen en el desarrollo del niño, como son las características de su entorno, de su familia y del propio niño. Y no sólo eso. Los resultados de algunas investigaciones aconsejan ser prudentes y no presuponer que el comportamiento parental constituye el factor principal (English et al., 2005; Haskett, Nears, Ward y McPherson, 2006; Maniglio, 2009).

Es preciso seguir investigando y avanzando en este terreno. Es preciso estar en permanente apertura a las nuevas aportaciones y conocimientos que con seguridad seguirán generándose. Pero estamos convencidos de que los criterios presentados en este artículo constituyen un avance y serán de utilidad para los profesionales de los Servicios de Protección Infantil y de la salud mental de nuestro país.

\section{Referencias}

Amaya-Jackson, L., Socolar, R. R. S., Hunter, W., Runyan, D. K. y Colindres, R. (2000). Directly questioning children and adolescents about maltreatment. A review of survey measures used. Journal of Interpersonal Violence, 15, 725-759.

American Psychiatric Association (2002). DSM-IV-TR. Manual diagnóstico y estadístico de los trastornos mentales. Barcelona: Masson.

American Professional Society on the Abuse of Children (1995). Psychosocial evaluation of suspected psychological maltreatment in children and adolescents. Practice guidelines. Chicago: APSAC.

Ayuntamiento de Madrid (2008). Manual de intervención de los Servicios Sociales del Ayuntamiento de Madrid para la protección de menores. Dirección General de Familia, Infancia y Voluntariado, Ayuntamiento de Madrid. Accesible en: http://www.munimadrid.es/portal/site/mu nimadrid/

Baker, A. J. L. (2009). Adult recall of childhood psychological maltreatment: Definitional strategies and challenges. Children and Youth Services Review, 31, 703-714.

Baker, A. J. L. y Festinger, T. (2011). Adult recall of childhood psychological maltreatment: A comparison of five scales. Journal of Aggression, Maltreatment \& Trauma, 20,69-88.

Barnett, D., Manly, J. T. y Cicchetti, D. (1991). Continuing toward an operational definition of psychological maltreatment. Development and Psychopathology, 3, 19-30.

Belsky, J. (1991). Psychological maltreatment: Definitional limitations and unstated assumptions. Development and Psychopathology, 3, 31-36.

Binggeli, N. J., Hart, S. N. y Brassard, M. R. (2001). Psychological maltreatment of children: The APSAC study guides 4. Thousand Oaks: Sage Publications.

Brassard, M. R. y Donovan, K. L. (2006). Defining psychological maltreatment. En M. M. Feerick, J. F. Knutson, P. K. Trickett y S. M. Flanzer (Eds.), Child abuse and neglect. Definitions, classifications, and a framework for research (pp. 151-197). Baltimore: Paul H. Brookes Publishing Co.

Chaffin, M. (2006). The changing focus of child maltreatment research and practice within psychology. Journal of Social Issues, 62, 663-684.

Chalk, R. (2006) Defining child abuse and neglect. A search for consensus. En M. M. Feerick, J. F. Knutson, P. K. Trickett y S. M. Flanzer (Eds.), Child abuse and neglect. Definitions, classifications, and a framework for research (pp. 29-47). Baltimore: Paul H. Brookes Publishing Co.

Child Welfare Information Gateway (2007). Definitions of child abuse and neglect: Summary of state laws. Washington DC: US Department of Health and Human Services. Accesible en: http://www.childwelfare.gov/systemwide/laws_policies/statutes/defineall.pdf

Children's Bureau of Southern California (1997). Family Assessment Form. A practice-based approach to assessing family functioning. Washington, DC: CWLA Press.

Diputación Foral de Álava (2004). Guía de actuación para los Servicios Sociales dirigidos a la infancia en el territorio histórico de Álava. Departamento de Asuntos Sociales, Diputación Foral de Álava. Accesible en: http://www.alava.net/cs/Satellite?c=IFBS_Generico_FA $\&$ cid $=1223988017985 \&$ pageid $=500002131563 \&$ page name $=I F B S \% 2 F I F B S \_G e n e r i c o \_F A \% 2 F I F B S \_g e n e r i c o$

Diputación Foral de Bizkaia (2005). Intervención en situaciones de desprotección infantil. Departamento de Acción Social, Diputación Foral de Bizkaia. Accesible en: http://www.bizkaia.net/Home2/Archivos/DPTO3/ Temas/Pdf/MANUAL.pdf

Diputación Foral de Gipuzkoa (2003). Guía de actuación en situaciones de desprotección infantil. Recepción, investigación, evaluación inicial y elaboración del plan de intervención. Departamento para los Derechos Humanos, el Empleo y la Inserción Social, Diputación Foral de Gipuzkoa.

Doyal, L. y Gough. I. (1994). Teoría de las necesidades humanas. Madrid: Editorial Icaria.

Dubowitz, H. (2006). Defining child neglect. En M. M. Feerick, J. F. Knutson, P. K. Trickett y S. M. Flanzer (Eds.), Child abuse and neglect. Definitions, classifications, and a framework for research (pp. 107-127). Baltimore: Paul H. Brookes Publishing Co. 
Egeland, B. (1991). From data to definition. Development and Psychopathology, 3, 37-43.

English, D. J., Upadhyaya, M. P., Litrownik, A. J., Marshall, J. M., Runyan, D. K., Graham, J. C. y Dubowitz, H. (2005). Maltreatment's wake: The relationship of maltreatment dimensions to child outcomes. Child Abuse \& Neglect, 29, 597-619.

English, D. J. y the LONGSCAN Investigators (1997). Modified Maltreatment Classification System (MMCS). Accesible en: http://www.iprc.unc.edu/longscan/pages/ mmcs/LONGSCAN\%20MMCS\%20Coding.pdf

Erickson, M. F. y Egeland, B. (2002). Child neglect. En J. E. B. Myers, L. Berliner, J. Briere, C. T. Hendrix, C. Jenny y T. A. Reid (Eds.), The APSAC handbook on child maltreatment (second edition) (pp. 3-20). Thousand Oaks: Sage Publications.

Euser, E. M., van Ijzendoorn, M. H., Prinzie, P. y BakermansKranenburg, M. J. (2010). Prevalence of child maltreatment in the Netherlands. Child Maltreatment, 15, 5-17.

Federación de Asociaciones para la Prevención del Maltrato Infantil (2010). Datos disponibles sobre maltrato infantil. 2008. Cuadernos de Bienestar y Protección Infantil, 5. Accesible en: http://www.fapmi. es/imagenes/subsecciones1/Cuadernos_05_Datos\%202008.pdf

Feiring, C. y Zielinski, M. (2011). Looking back and looking forward: A review and reflection on research articles published in Child Maltreatment from 1996 through 2010. Child Maltreatment, 16, 3-8.

Garbarino, J., Guttmann, E. y Seeley, J. W. (1986). The psychologically battered child. Strategies for identification, assessment, and intervention. San Francisco: Jossey-Bass Inc. Publishers.

Glaser, D. (2002). Emotional abuse and neglect (psychological maltreatment): A conceptual framework. Child Abuse \& Neglect, 26, 697-714.

Gobierno de Cantabria (2006). Manual Cantabria. Actuaciones en situaciones de desprotección infantil. Principios generales. Dirección General de Políticas Sociales, Gobierno de Cantabria. Accesible en: http://www. serviciossocialescantabria.org/uploads/documentos\%20e\%20informes/01.Manual\%20Cantabria\%20(PR INCIPIOS\%20GENERALES)_dic2006.pdf

Gobierno de Navarra (2003). Manual de intervención en situaciones de desprotección infantil en la Comunidad Foral de Navarra. Departamento de Bienestar Social, Deporte y Juventud, Gobierno de Navarra. Accesible en: http://www.navarra.es/NR/rdon lyres/9D13E4D1-10344614-9704-A84DC4FA 76F4/91963/00Indice.pdf

Gobierno del Principado de Asturias (2008). Guía de buena práctica en la intervención social con la infancia, familias y adolescencia. Desprotección infantil. Manual de procedimiento de intervención ante situaciones de desprotección infantil para los servicios sociales de Asturias. Consejería de Bienestar Social, Gobierno del Principado de Asturias. Accesible en: http://tematico.asturias.es/websociales/ documentos/guiamanualdesprotecci\%C3\%B3n.pdf

Gómez de Terreros, M. (2006). Maltrato psicológico. Cuadernos de Medicina Forense, 12, 103-116.
Hart, S. N., Brassard, M. R., Binggeli, N. J. y Davidson, H. A. (2002). Psychological maltreatment. En J. E. B. Myers, L. Berliner, J. Briere, C. T. Hendrix, C. Jenny y T. A. Reid (Eds.), The APSAC handbook on child maltreatment (second edition) (pp. 79-104). Thousand Oaks: Sage Publications.

Haskett, M. E., Nears, K., Ward, C. S. y McPherson, A. V. (2006). Diversity in adjustment of maltreated children: Factors associated with resilient functioning. Clinical Psychology Review, 26, 796-812.

Herrenkohl, R. C. y Herrenkohl, T. I. (2009). Assessing a child's experience of multiple maltreatment types: Some unfinished business. Journal of Family Violence, 24, 485-496.

International Society for Prevention of Child Abuse and Neglect (1999). Definition of CAN. Accesible en: http://www.ispcan.org/CAN-facts/definition.html

International Society for Prevention of Child Abuse and Neglect (2008). World perspectives on child abuse. Chicago: ISPCAN.

Junta de Castilla y León (1995). Manual de intervención en situaciones de desamparo. Detección, notificación, recepción, investigación, evaluación, plan de caso, intervención. Consejería de Sanidad y Bienestar Social, Junta de Castilla y León.

Kairys, S. W., Johnson, C. F. y Committee on Child Abuse and Neglect (2002). The psychological maltreatment of children - Technical report. Pediatrics, 109, 1-3. Accesible en: http://pediatrics.aappublications. org/cgi/ reprint/109/4/e68

Little, M., Axford, N. y Morpeth, L. (2003). Threshold. Determining the extent of impairment to children's development. Totnes: Warren House Press.

López, F. (1995). Necesidades de la infancia y protección infantil I. Fundamentación teórica, clasificación y criterios educativos de las necesidades infantiles. Madrid: Ministerio de Asuntos Sociales.

López, F. (2008). Necesidades en la infancia y en la adolescencia. Respuesta familiar, escolar y social. Madrid: Pirámide.

Magura, S. y Moses, B. S. (1986). Outcome measures for child welfare services: Theory and applications. Washington, DC: Child Welfare League of America.

Maniglio, R. (2009). The impact of child sexual abuse on health: A systematic review of reviews. Clinical Psychology Review, 29, 647-657.

McGee, R. A. y Wolfe, D. A. (1991). Psychological maltreatment: Toward an operacional definition. Development and Psychopathology, 3, 3-18.

O'Hagan, K. (1993). Emotional and psychological abuse of children. Buckingham: Open University Press.

Ontario Association of Children's Aid Societies (2006). Eligibility Spectrum. Accesible en: http://www.oacas.org/ pubs/oacas/eligibility/index.htm

Organización Mundial de la Salud (2001). Clasificación Multiaxial de los trastornos psiquiátricos en niños y adolescentes. Clasificación de la CIE-10 de los trastornos mentales y del comportamiento en niños y adolescentes. Buenos Aires: Editorial Médica Panamericana. 
Palacios, J. (1995). Los datos del maltrato infantil en España: Una visión de conjunto. Infancia y Aprendizaje, 71, 69-76.

Pearce, J. W. y Pezzot-Pearce, T. D. (1997). Psychotherapy of abused and neglected children. New York: The Guildford Press.

Portwood, S. G. (2006). Self-report approaches. En M. M. Feerick, J. F. Knutson, P. K. Trickett y S. M. Flanzer (Eds.), Child abuse and neglect. Definitions, classifications, and a framework for research (pp. 233-254). Baltimore: Paul H. Brookes Publishing Co.

Runyan, D. K. y English, D. J. (2006). Measuring child abuse and neglect using Child Protective Services records. En M. M. Feerick, J. F. Knutson, P. K. Trickett y S. M. Flanzer (Eds.), Child abuse and neglect. Definitions, classifications, and a framework for research (pp. 255-292). Baltimore: Paul H. Brookes Publishing Co.

Slep, A. M. S. y Heyman, R. E. (2006). Creating and fieldtesting child maltreatment definitions: Improving the reliability of substantiation determinations. Child Maltreatment, 11, 217-236.

Srivastava, O. P. y Polnay, S. (1997). Field trial of graded care profile (GCP) scale: A new measure of care. Archives of Disease in Childhood, 76, 337-340.

Stwoman, S. A. y Donohue, B. (2005). Assessing child neglect: A review of standardized measures. Aggression and Violent Behavior, 10, 491-512.

Trocmé, N. (1996). Development and preliminary evaluation of the Ontario Child Neglect Index. Child Maltreatment, $1,145-155$.

UK Government (2000). Framework for the assessment of children in need and their families. London, Department of Health, UK Government. Accesible en: http://www.dh. gov.uk/en/Publicationsandstatistics/Publications/Publica tionsPolicyAndGuidance/DH_4003256

US Department of Health and Human Services (2009). Fourth National Incidence Study of Child Abuse and Neglect (NIS4), 2004-2009. Accesible en: http://www. acf.hhs.gov/programs/opre/abuse_neglect/natl_incid/index.html

\section{Notas}

${ }^{1} \mathrm{El}$ artículo utiliza de forma genérica el término "niño" para referirse a los niños, niñas y adolescentes, y el término "padres" para referirse a los padres, madres o responsables legales de un niño.

${ }^{2}$ La Education of All Handicapped Children Act (PL-94-142) fue aprobada por el congreso estadounidense en el año 1975. En ella se define la perturbación emocional severa como una condición que presenta una o más de las siguientes características, manifestadas durante un período prolongado de tiempo y con una intensidad notoria, que afecta negativamente al rendimiento académico del niño:

- Incapacidad para el aprendizaje que no puede ser explicada por factores intelectuales, sensoriales u orgánicos.

- Incapacidad para establecer o mantener relaciones interpersonales satisfactorias con iguales y profesores.

- Sentimientos o comportamientos inapropiados en circunstancias normales.

- Estado general constante de infelicidad o depresión.

- Tendencia a desarrollar miedos o síntomas físicos asociados con problemas personales o escolares.

Esta ley fue modificada en el año 1997 (PL 105-17), sustituyéndose la expresión perturbación emocional severa por perturbación emocional. El significado legal de ambas expresiones se mantuvo idéntico. El cambio se produjo para eliminar cualquier connotación negativa del término severa. El documento original se encuentra en http://www. scn.org/ bk269/94-142.html 
Apéndice I. Instrumento Balora para la valoración de la gravedad de las situaciones de riesgo y desamparo: Escalas de Negligencia hacia necesidades psíquicas y Maltrato psíquico

\section{NEGLIGENCIA HACIA NECESIDADES PSÍQUICAS}

Definición: Desatención a las necesidades del niño de interacción y afecto, estimulación, y guía y orientación, así como rechazo o retraso en la provisión de atención psicológica o psiquiátrica a problemas emocionales graves.

\section{Situaciones que implican gravedad muy elevada, elevada y moderada}

\section{A. INTERACCIÓN Y AFECTO}

$\Rightarrow$ La gravedad de la negligencia en relación a este tipo de necesidades se determina en función de (a) la intensidad y frecuencia del comportamiento negligente de los padres, (b) la edad del niño, y (c) la gravedad de las secuelas observables en él.

$\Rightarrow$ En situaciones en que la gravedad del comportamiento negligente de los padres es moderada (véase primer epígrafe de dicha categoría) pero el niño sufre un daño psíquico grave como consecuencia de ello, la gravedad se calificará como elevada.

\section{Gravedad muy elevada}

- Los padres ignoran los intentos y necesidades del niño de interactuar (ausencia de expresión de afecto, cuidado, y amor hacia él) y no reflejan ninguna o escasa emoción en las interacciones con él. Incluye: (a) tener desapego y falta total de implicación respecto al niño, bien por incapacidad o por falta de motivación, (b) interactuar sólo cuando es absolutamente necesario, y (c) ausencia total de expresiones de afecto, cuidado, y amor. Los momentos de interacción adecuada 0 atención a las necesidades emocionales del niño son inexistentes, esporádicos 0 escasos. Los intentos del niño por obtener la atención de sus padres pueden acabar en hostilidad. Nunca o raramente están disponibles para ayudar al niño cuando lo necesita o cuando requiere guía u orientación. Tienden a no prestar atención o a mostrarse indiferentes ante sus intentos por conversar o incorporarles a sus actividades. $\underline{\mathbf{Y}}$

- Esta situación se produce de manera continuada, intensa y claramente perceptible, caracterizando la relación entre los padres y el niño. $\underline{Y}$

- No hay figuras alternativas en el entorno familiar que proporcionen una atención adecuada a las necesidades de interacción y afecto del niño y compensen esos déficits. $\underline{Y}$

- En niños mayores de seis años y adolescentes: El niño sufre un daño psíquico grave y hay datos razonables para pensar que es consecuencia del patrón de negligencia de sus padres. La valoración de la gravedad es independiente de que los padres busquen o accedan a que el niño reciba atención psicológica o psiquiátrica.

En niños menores de seis años: La gravedad se calificará como muy elevada independientemente de que el niño muestre o no síntomas de daño psíquico o retraso en el desarrollo de carácter grave.

\section{Gravedad elevada}

- Se dan las circunstancias descritas como "gravedad muy elevada" hacia un niño mayor de seis años pero, aunque presenta síntomas de daño psíquico, no son de carácter grave. Sin embargo, estos síntomas no sólo no mejoran, sino que evolucionan hacia una mayor gravedad y hay datos razonables para pensar que son consecuencia del patrón de negligencia de sus padres. La valoración de la gravedad es independiente de que los padres busquen o accedan a que el niño reciba atención psicológica o psiquiátrica. $\underline{\mathbf{0}}$

- Se dan las circunstancias descritas como "gravedad moderada" en relación al comportamiento de los padres y a la ausencia de figuras alternativas en el entorno familiar que compensen sus déficits (ver los dos primeros epígrafes). Aunque la situación no es extrema, el niño sufre un daño psíquico grave y hay datos razonables para pensar que es consecuencia del patrón de negligencia de sus padres. La valoración de la gravedad es independiente de que los padres busquen o accedan a que el niño reciba atención psicológica o psiquiátrica.

\section{Gravedad moderada}

- De forma frecuente, los padres ignoran los intentos y necesidades de interactuar del niño (ausencia de expresión de afecto, cuidado, y amor) y no reflejan ninguna o escasa emoción en las interacciones con él. Es también frecuente que no estén disponibles para ayudar al niño cuando lo necesita o cuando requiere guía u orientación. Sin embargo, esta situación se alterna con períodos o momentos en que la interacción es adecuada. $\underline{Y}$

- No hay figuras alternativas en el entorno familiar que proporcionen una atención adecuada a las necesidades emocionales del niño y compensen esos déficits. $\underline{Y}$

- El niño se encuentra en una situación de riesgo de sufrir un daño psíquico grave y hay datos razonables para pensar que dicho riesgo es consecuencia del patrón de negligencia de sus padres. El niño puede presentar conductas problemáticas de carácter no severo; estas conductas pueden constituir estrategias para obtener atención.

\section{B. ESTIMULACIÓN}

$\Rightarrow$ La gravedad de la negligencia en relación a este tipo de necesidades se determina en función de (a) la intensidad y frecuencia del comportamiento negligente de los padres, (b) la edad del niño, y (c) la gravedad de las secuelas observables en él.

$\Rightarrow$ En situaciones en que la gravedad del comportamiento negligente de los padres es moderada (véase primer epígrafe de dicha categoría) pero el niño sufre un daño psíquico grave como consecuencia de ello, la gravedad se calificará como elevada.

1. Gravedad muy elevada

- Los padres no proporcionan al niño experiencias enriquecedoras o educativas fuera del ámbito escolar dirigidas a desarrollar sus habilidades cognitivas o responder a sus necesidades de estimulación y aprendizaje. Interfieren con los intentos del niño por alcanzar logros evoluti- 
vamente normales o muestran muy poco interés por ello (p.ej., tener al niño en la cuna durante prácticamente todo el tiempo, no promover el desarrollo del lenguaje o de sus capacidades físicas o intelectuales, no proporcionarle instrumentos de juego o aprendizaje apropiados a la edad, no reconocer su necesidad de jugar o realizar actividades lúdicas, no responder a sus preguntas, no presentarle estímulos nuevos). Normalmente prefieren que se entretenga solo con juguetes, juegos, la televisión o similar. La comunicación es monosilábica o muy limitada o es de naturaleza correctiva (destacar los errores) en lugar de ser constructiva (razonar y mostrar el camino adecuado). $\underline{\mathbf{Y}}$

- Esta situación se produce de manera continuada, intensa y claramente perceptible, caracterizando la relación entre los padres y el niño. $\underline{\mathbf{Y}}$

- No hay figuras alternativas en el entorno familiar que proporcionen una atención adecuada a las necesidades de estimulación del niño y compensen esos déficits. $\underline{Y}$

- En niños mayores de seis años: El niño sufre un daño psíquico grave y hay datos razonables para pensar que es consecuencia del patrón de negligencia de sus padres. La valoración de la gravedad es independiente de que los padres busquen o accedan a que el niño reciba atención psicológica o psiquiátrica.

En niños menores de seis años: La gravedad se calificará como muy elevada independientemente de que el niño muestre o no síntomas de daño psíquico o retraso en el desarrollo de carácter grave.

\section{Gravedad elevada}

- Se dan las circunstancias descritas como "gravedad muy elevada" hacia un niño mayor de seis años pero, aunque éste presenta síntomas de daño psíquico, no son de carácter grave. Sin embargo, estos síntomas no sólo no mejoran, sino que evolucionan hacia una mayor gravedad y hay datos razonables para pensar que son consecuencia del patrón de negligencia de sus padres. La valoración de la gravedad es independiente de que los padres busquen o accedan a que el niño reciba atención psicológica o psiquiátrica. $\underline{\mathbf{0}}$

- Se dan las circunstancias descritas como "gravedad moderada" en relación al comportamiento de los padres y a la ausencia de figuras alternativas en el entorno familiar que compensen sus déficits (ver los dos primeros epígrafes). Aunque la situación no es extrema, el niño sufre un daño psíquico grave y hay datos razonables para pensar que es consecuencia del patrón de negligencia de sus padres. La valoración de la gravedad es independiente de que los padres busquen o accedan a que el niño reciba atención psicológica o psiquiátrica.

\section{Gravedad moderada}

- Los padres no proporcionan de forma suficientemente consistente al niño experiencias enriquecedoras o educativas fuera del ámbito escolar dirigidas a desarrollar sus habilidades cognitivas o responder a sus necesidades de estimulación y aprendizaje. Muestran poca iniciativa en que el niño alcance logros evolutivamente normales, aunque permiten sus iniciativas. Normalmente prefieren que aprenda o se entretenga solo con juguetes, juegos o la televisión. Le dejan ver cualquier programa en la televisión, aunque pueden desaprobarlo verbalmente. Conceden poca importancia al juego o a las actividades lúdicas; raramente juegan o comparten este tipo de actividades con el niño pero le permiten hacerlo. Hay cierta restricción a la espontaneidad. Permiten que el niño se desarrolle con una mínima guía por su parte. La comunicación es limitada y depende en general del estado de humor de los padres. No hay una atención consistente y suficiente a las necesidades de estimulación y aprendizaje del niño. $\underline{\mathbf{Y}}$

- Esta situación se produce de manera frecuente, aunque se alterna con momentos de interacción adecuada. $\underline{\mathbf{Y}}$

- No hay figuras alternativas en el entorno familiar que proporcionen una atención adecuada a las necesidades del niño y compensen esos déficits. $\underline{Y}$

- El niño se encuentra en una situación de riesgo de sufrir un daño psíquico o un retraso en el desarrollo graves y hay datos razonables para pensar que dicho riesgo es consecuencia del patrón del patrón de negligencia de sus padres.

\section{ATENCIÓN ESPECÍFICA A PROBLEMAS EMOCIONALES GRAVES}

$\Rightarrow$ La gravedad de la negligencia en relación a este tipo de necesidades se determina en función de (a) la presencia de desatención clara por parte de los padres a la necesidad del niño de recibir tratamiento psicológico o psiquiátrico por la presencia de problemas emocionales graves, y (b) la severidad de tales problemas.

$\Rightarrow$ En esta tipología no hay calificación de gravedad moderada.

1. Gravedad muy elevada

- Los padres rechazan, se inhiben o actúan con un grave retraso en la búsqueda de tratamiento psicológico o psiquiátrico para problemas emocionales de gravedad extrema en el niño que ponen en riesgo su vida (p.ej., depresión severa, intento de suicidio) que requieren tratamiento imprescindible y urgente. $\underline{\mathbf{O}}$ no cumplen o son notoriamente inconsistentes en el seguimiento de las indicaciones de los profesionales que le están proporcionando tratamiento. Los problemas del niño pueden tener o no su origen en el trato recibido en la familia.

\section{Gravedad elevada}

- Los padres rechazan, se inhiben o actúan con un grave retraso en la búsqueda de tratamiento psicológico o psiquiátrico para problemas emocionales graves en el niño que, aunque no ponen en riesgo su vida, requieren tratamiento imprescindible. $\underline{\mathbf{O}}$ no cumplen o son notoriamente inconsistentes en el seguimiento de las indicaciones de los profesionales que le están proporcionando tratamiento. Los problemas del niño pueden tener o no su origen en el trato recibido en la familia.

\section{NORMAS, LÍMITES Y TRANSMISIÓN DE VALORES MORALES POSITIVOS}

$\Rightarrow$ "Transmisión de valores morales positivos" se refiere a promover conductas de respeto hacia los derechos de los demás.

$\Rightarrow$ La gravedad de la negligencia en relación a este tipo de necesidades se determina en función de (a) el grado de desatención por parte de los padres a este tipo de necesidades del niño, y (b) la presencia de problemas comportamentales y de adaptación personal, familiar y/o social en él o el riesgo de que tales problemas aparezcan en el futuro próximo. 


\section{Gravedad muy elevada}

- Los padres se inhiben totalmente en su función de poner límites y/u orientar adecuadamente la conducta del niño. La ausencia de límites y normas es absoluta y continuada. No hay transmisión de normas de comportamiento y valores morales positivos. $\underline{\mathbf{Y}}$

- El niño presenta graves problemas comportamentales y de adaptación personal, familiar y/o social que son consecuencia de esta situación o se ven reforzados por ella.

\section{Gravedad elevada}

- Los padres raramente ponen límites y normas y/u orientan adecuadamente la conducta del niño, o las normas y límites son claramente inapropiados y dañinos para él por su excesiva restricción o laxitud, que puede ir acompañada de inconsistencia. No hay transmisión de normas de comportamiento y valores morales positivos. $\underline{Y}$

- El niño presenta graves problemas comportamentales y de adaptación personal, familiar y/o social que son consecuencia de esta situación o se ven reforzados por ella.

\section{Gravedad moderada}

- Los padres raramente ponen límites y normas y/u orientan adecuadamente la conducta del niño o las normas y límites son con frecuencia claramente inapropiados para él por su excesiva restricción o laxitud, que puede ir acompañada de inconsistencia. $\underline{\mathbf{Y}}$

- El niño puede presentar problemas incipientes de comportamiento o adaptación personal, familiar y/o social que se valora pueden agravarse como consecuencia de esta situación, o se considera muy probable que tales problemas aparezcan en el futuro próximo.

\section{Situaciones que implican riesgo leve 0 ausencia de negligencia \\ (descripción genérica para el conjunto de escalas de Negligencia hacia necesidades psíquicas)}

\section{Riesgo leve}

- Los padres prestan una atención insuficiente a algunas de las necesidades psíquicas del niño (afectivas, de comunicación, de estimulación, guía y orientación, límites a la conducta, transmisión de normas de comportamiento y valores morales). Se relacionan con él cuando tienen tiempo, priorizando de manera frecuente sus propias necesidades a las del niño. Implica conductas socialmente toleradas (p.ej., interacción y comunicación cotidiana prácticamente inexistente o muy limitada con el niño, excesiva delegación de su cuidado en terceras personas) que, aunque no han provocado síntomas de daño psíquico o retraso en el desarrollo en el niño, implican carencias perjudiciales para su desarrollo óptimo que pueden derivar en el futuro en problemas emocionales y comportamentales significativos.

- Conductas que implican una falta de respeto a la necesidad de intimidad física del niño (p.ej., excesiva desinhibición en relación a cuestiones de índole sexual, personas adultas que se bañan o comparten cama con niños ya mayores habiendo oportunidad y espacio para hacerlo de forma independiente), pero sin intención de carácter sexual y sin que el niño las perciba como amenazantes o inapropiadas.

\section{No presente}

- Aunque ocasionalmente pueda haber elementos negativos en la relación de los padres hacia el niño y se produzcan algunas de las conductas calificadas como negligencia hacia las necesidades psíquicas, éstas son de baja intensidad y esporádicas. La interacción entre los padres y el niño se caracteriza por el conocimiento, toma en consideración y atención adecuada a sus necesidades psíquicas.

\section{MALTRATO PSÍQUICO}

Definición: El niño ha sufrido un daño psíquico grave o hay riesgo de que lo sufra como consecuencia de las acciones de sus padres. En determinados casos - ver escala de "Exposición a situaciones de violencia de pareja o entre miembros de la unidad convivencial"- incluye también las acciones de otras personas que forman parte de la unidad convivencial.

\section{A. MALTRATO EMOCIONAL}

$\Rightarrow$ En general esta tipología no se define en base a un incidente aislado -salvo si se trata de un incidente o situación con un alto contenido traumáticosino como un patrón reiterado o continuado de conductas negativas o de interacciones destructivas de los padres hacia el niño que provocan en él un daño psíquico grave o le colocan en riesgo de padecerlo.

$\Rightarrow$ Tipos de conductas que incluye:

- Rechazar. Actos verbales o no verbales que rechazan o degradan al niño. Incluye:

- Despreciar, insultar, degradar, y otras formas no físicas de tratamiento hostil o rechazante.

- Avergonzar y/o ridiculizar al niño por mostrar emociones normales, tales como afecto, dolor o tristeza.

- Escoger siempre a un determinado niño para criticarle y castigarle, para hacer la mayoría de las tareas domésticas, o para recibir menos premios.

- Humillación pública.

- Culpar al niño del suicidio, muerte, graves problemas físicos o mentales de un miembro de la familia, violencia de pareja o similares.

- Aterrorizar. Amenazar al niño con un castigo extremo o uno vago pero siniestro o con abandonarle, con el propósito de crear en él un miedo intenso. O colocarle o amenazarle con colocarle a él o a personas u objetos a los que quiere, en situaciones evidentemente peligrosas o que le provocan un miedo intenso. Incluye:

- Colocarle o amenazarle con colocarle en circunstancias impredecibles, caóticas o que le provocan un miedo intenso (nota: cuando el niño sea amenazado con una agresión física, se calificará en la escala de "Amenazas de agresión física").

- Establecer hacia él unas expectativas rígidas o no realistas, con la amenaza de pérdida, daño o peligro si esas expectativas no se alcanzan.

- Amenazar o cometer violencia contra el niño o contra personas u objetos queridos por él. 
- Aislar. Negar al niño las oportunidades para satisfacer sus necesidades de interactuar y comunicarse con iguales o con otras personas adultas dentro o fuera del hogar. Incluye:

- Confinar al niño o poner limitaciones no razonables sobre su libertad de movimiento en su entorno.

- Ponerle limitaciones o restricciones no razonables respecto a la relación con iguales u otras personas adultas en la comunidad.

- Restricción de la autonomía. Coartar o impedir al niño alcanzar las cotas de autonomía y participación adecuadas a su edad, promoviendo o permitiendo conductas evolutivamente inapropiadas. Incluye:

- Sobreimplicación, intrusividad y/o dominación extremas sobre el niño, sin permitirle expresar sus sentimientos, opiniones o deseos o creando un "micro-mundo" para él. Incluye relaciones simbióticas o fusionales.

- Infantilización o parentalización (nota: se define "parentalización" como la asignación del rol parental al niño; implica inversión de roles y ausencia de límites claros entre los subsistemas parental y filial; el niño asume un papel de adulto en el que sacrifica sus propias necesidades y tareas evolutivas para satisfacer necesidades emocionales y de apoyo de sus padres).

- Utilización del niño para la materialización de los deseos no cumplidos de los adultos.

- Sobreexigencia.

- Sometimiento al niño a una presión excesiva en cuanto a los logros (académicos, físicos, comportamentales, etc.) a alcanzar o a las responsabilidades a asumir, estando éstos claramente por encima de sus posibilidades y capacidades dada su edad y características o, estando a su alcance, suponiéndole un estrés muy elevado y/o grave restricción de otras necesidades o actividades propias de su estadio evolutivo. El niño puede ser castigado o retirársele el afecto de sus padres por no cumplir las expectativas.

- Los padres asignan al niño de forma habitual la realización de trabajos domésticos o de cuidado de otros niños o personas enfermas o discapacitadas. No asiste a la escuela por este motivo y/o no dispone apenas de tiempo para actividades lúdicas y descanso. Puede que estas tareas le sean asignadas fuera del horario escolar o en período festivo, implicando una limitación o restricción total o prácticamente total de su tiempo libre y de sus oportunidades de relacionarse con iguales.

- Transmisión de impredecibilidad, inestabilidad, inseguridad respecto al futuro inmediato. A través de la conducta o de mensajes verbales, se traslada al niño una grave inseguridad sobre aspectos fundamentales de su futuro inmediato (p.ej., estabilidad de sus figuras adultas de referencia, unidad del núcleo familiar; niños en guarda de hecho que reciben amenazas repetidas de sus padres de ser separados de sus figuras guardadoras). La inseguridad puede ser fundada o infundada. Se incluyen casos de Síndrome de Munchausen por poderes en los que se transmite directa o indirectamente al niño el mensaje continuado de que su salud está en grave peligro.

$\Rightarrow$ La gravedad del maltrato emocional se determina en función de (a) la intensidad y frecuencia del comportamiento maltratante de los padres, (b) la edad del niño, y (c) la gravedad de las secuelas observables en él.

$\Rightarrow$ En situaciones en que la intensidad del comportamiento de los padres es moderada (véase primer epígrafe de dicha categoría) pero el niño sufre un daño psíquico grave como consecuencia de ello, la gravedad se calificará como elevada.

1. Gravedad muy elevada

- Los padres han protagonizado en presencia del niño un acto extremo de maltrato emocional de alto contenido traumático (por ejemplo, intento de suicidio, torturar o matar a un animal querido por el niño para castigarle). El niño ha sufrido un miedo y ansiedad intensos; puede presentar síntomas de un trastorno por estrés postraumático.

- Las conductas de maltrato emocional se producen de manera continuada, intensa y claramente perceptible, caracterizando la relación entre al menos una de las figuras parentales y el niño. Los momentos de interacción adecuada o atención a las necesidades emocionales de éste son inexistentes o esporádicos. $\underline{Y}$

- No hay figuras alternativas en el entorno familiar que proporcionen una atención adecuada a dichas necesidades y compensen esos déficits. $\underline{\mathbf{Y}}$

- En niños mayores de seis años: El niño sufre un daño psíquico grave y hay datos razonables para pensar que es consecuencia de las acciones de sus padres. La valoración de la gravedad es independiente de que los padres busquen o accedan a que el niño reciba atención psicológica o psiquiátrica.

En niños menores de seis años: La gravedad se calificará como muy elevada independientemente de que el niño muestre o no síntomas de daño psíquico o retraso en el desarrollo de carácter grave.

2. Gravedad elevada

- Se dan las circunstancias descritas en el segundo apartado de "gravedad muy elevada" hacia un niño mayor de seis años pero, aunque el niño presenta síntomas de daño psíquico, no son de carácter grave. Sin embargo, estos síntomas no sólo no mejoran, sino que evolucionan hacia una mayor gravedad y hay datos razonables para pensar que son consecuencia de las acciones de sus padres. La valoración de la gravedad es independiente de que los padres busquen o accedan a que el niño reciba atención psicológica o psiquiátrica. $\underline{\mathbf{O}}$

- Se dan las circunstancias descritas como "gravedad moderada" en relación al comportamiento de los padres y a la ausencia de figuras alternativas en el entorno familiar que compensen sus déficits (ver los dos primeros párrafos). Aunque la situación no es extrema, el niño sufre un daño psíquico grave y hay datos razonables para pensar que es consecuencia de las acciones de sus padres. La valoración de la gravedad es independiente de que los padres busquen o accedan a que el niño reciba atención psicológica o psiquiátrica.

3. Gravedad moderada

- Las conductas de maltrato emocional se producen de manera repetida, aunque se alternan con períodos o momentos en que la interacción es adecuada. $\underline{Y}$

- No hay figuras alternativas en el entorno familiar que proporcionen una atención adecuada a las necesidades emocionales del niño y compensen esos déficits. $\underline{Y}$

- El niño se encuentra en una situación de riesgo de sufrir un daño psíquico grave y hay datos razonables para pensar que dicho riesgo es consecuencia de las acciones de sus padres. El niño puede presentar conductas problemáticas de carácter no severo. Si la situación no se corrige, dichas conductas pueden evolucionar hacia una mayor gravedad.

4. Riesgo leve

- Las conductas de maltrato emocional por parte de los padres se producen de manera repetida, aunque se alternan con períodos o momentos en que la interacción con el niño es adecuada. Sin embargo, hay figuras alternativas en el entorno familiar que proporcionan una atención adecuada a las necesidades emocionales del niño y compensan esos déficits. El niño no manifiesta síntomas de daño psíquico. 


\section{No presente}

- Aunque ocasionalmente pueda haber elementos afectivos negativos en la relación de los padres hacia el niño y se produzcan algunas de las conductas calificadas como maltrato emocional, son de baja intensidad y esporádicas. La interacción entre las figuras parentales y el niño se caracteriza por el conocimiento, toma en consideración y atención adecuada a sus necesidades afectivas.

\section{B. INSTRUMENTALIZACIÓN EN CONFLICTOS ENTRE LAS FIGURAS PARENTALES}

$\Rightarrow$ Implica la utilización activa del niño por los padres para dañarse mutuamente y/o alejarle definitivamente de la otra figura parental. Incluye también los casos en que la utilización se produce únicamente por parte de una de las figuras parentales, la otra parte quiere defender sus intereses, y los mecanismos/recursos judiciales puestos en marcha no resuelven el problema e incluso éste empeora. Esta situación perturba la capacidad y disposición del niño para establecer o mantener una relación adecuada y positiva con una o ambas figuras parentales.

$\Rightarrow$ La gravedad de esta tipología se determina en función de (a) la intensidad del comportamiento de los padres, y (b) su impacto en el niño y en la calidad de su relación con sus padres.

1. Gravedad muy elevada

- El niño es utilizado de forma constante o extremadamente intensa por al menos uno de los padres para dañar o conseguir algo de la otra figura parental. Como consecuencia de ello, presenta síntomas de daño psíquico grave o muestra un rechazo extremo e injustificado hacia una de las figuras parentales, y hay datos razonables para pensar que estos problemas son consecuencia de dicha situación.

2. Gravedad elevada

- Misma situación que "gravedad muy elevada", pero los síntomas de daño psíquico que presenta el niño no son de carácter grave aunque no sólo no mejoran, sino que evolucionan hacia una mayor gravedad y hay datos razonables para pensar que estos problemas son consecuencia de dicha situación. La situación está dificultando seriamente el establecimiento o el mantenimiento de un vínculo de apego positivo entre el niño y alguno de sus padres.

3. Gravedad moderada

- Misma situación que "gravedad muy elevada", pero el niño no presenta síntomas de daño psíquico ni perturbaciones en el vínculo de apego con sus padres. Se valora que hay una alta probabilidad de que esos síntomas se presenten en un futuro próximo si la situación no se corrige.

4. Riesgo leve

- En ocasiones los padres utilizan al niño para dañarse entre sí o conseguir algo del otro, pero eso no caracteriza su relación. En general, mantienen una relación adecuada con el niño. El niño puede encontrarse en ocasiones ante un conflicto de lealtades, pero no presenta síntomas de daño psíquico.

5. No presente

- A pesar de que pudiera existir conflicto, los padres no utilizan al niño para dañarse entre sí o conseguir algo del otro.

\section{EXPOSICIÓN A SITUACIONES DE VIOLENCIA DE PAREJA O ENTRE MIEMBROS DE LA UNIDAD CONVIVENCIAL}

$\Rightarrow$ Se calificará la existencia de esta tipología únicamente cuando ninguno de los padres sea capaz de adoptar las medidas necesarias para detener o controlar esta situación y proteger al niño alejándole de la situación de violencia.

$\Rightarrow$ La gravedad de esta tipología se determina en función de (a) la intensidad y frecuencia de la violencia física y verbal que se produce entre los padres o los miembros de la unidad convivencial y (b) la severidad del daño físico y psíquico que tales situaciones han provocado o pueden provocar en el niño.

1. Gravedad muy elevada

- El niño ha sido testigo de al menos una agresión física muy grave (la agresión ha provocado lesiones que han requerido ingresos hospitalarios, amenazas con armas potencialmente mortíferas, o similar) entre los padres o los miembros de la unidad convivencial.

- Ha habido episodios de violencia física muy grave (la agresión ha provocado lesiones que han requerido ingresos hospitalarios, amenazas con armas potencialmente mortíferas, o similar) entre los padres o los miembros de la unidad convivencial de los que el niño no ha sido testigo. No obstante, se valora que hay un riesgo elevado de que tales episodios se repitan y pongan en serio peligro la vida o integridad física del niño.

- En los últimos seis meses se han producido episodios de violencia física y episodios continuados de violencia verbal explícita e intensa entre los padres o los miembros de la unidad convivencial. El niño se ha implicado o ha sido implicado en estos episodios $\mathbf{y}$ ha sufrido un daño físico muy grave como consecuencia de ello.

2. Gravedad elevada

- En los últimos seis meses se han producido episodios de violencia física y episodios continuados de violencia verbal explícita e intensa entre los padres o los miembros de la unidad convivencial. El niño ha sido testigo de estos episodios o los ha percibido claramente $\underline{Y}$ :

- Ha sufrido un daño físico grave como consecuencia de esa situación, y/o

- Presenta síntomas de daño psíquico grave y hay datos razonables para pensar que son consecuencia de dicha situación.

3. Gravedad moderada

- Misma situación que el "gravedad elevada", pero el niño:

- No ha sufrido un daño físico grave o muy grave como consecuencia de esa situación, $\mathbf{y}$

- Puede presentar síntomas de daño psíquico asociados a esta situación que, aunque no son de carácter grave, se valora que hay una alta probabilidad de que se presenten en un futuro próximo si la situación no se corrige.

- En los últimos seis meses se han producido episodios frecuentes de violencia verbal entre los padres o los miembros de la unidad convivencial, pero no violencia física. El niño ha sido conocedor de algunos de esos episodios. Presenta síntomas de daño psíquico asociados a esta situación que, aunque no son de carácter grave, podrían evolucionar hacia una mayor gravedad si la situación no se corrige. A pesar de ello, los padres y los miembros de la unidad convivencial mantienen períodos o momentos de interacción adecuada con el niño. 


\section{Riesgo leve}

- En los últimos seis meses se han producido varios episodios de violencia verbal entre los padres o los miembros de la unidad convivencial, pero no violencia física. El niño ha sido conocedor o testigo de alguno de esos episodios, aunque las personas implicadas han procurado que no se produzcan en su presencia. Los padres y los miembros de la unidad convivencial mantienen en general una interacción adecuada con el niño. El niño no presenta síntomas de daño psíquico asociados a esta situación, aunque puede mostrar signos de malestar ante los episodios de violencia verbal.

5. No presente

- Los padres o los miembros de la unidad convivencial resuelven sus conflictos sin utilizar la violencia física o verbal. Aunque puede haber incidentes aislados de violencia verbal, el niño no es testigo de ellos.

\section{AMENAZAS DE AGRESIÓN FÍSICA}

$\Rightarrow$ La gravedad de esta tipología se determina en función de (a) la severidad del daño con el que se amenaza al niño, (b) el temor que las amenazas provocan en él, y (c) el riesgo de que las amenazas se materialicen.

\section{Gravedad muy elevada}

- Amenaza directa de daño físico extremadamente grave, sin daño real: Se ha colocado al menos en una ocasión al niño en situaciones muy peligrosas (p.ej., al borde de una ventana, sobre agua hirviendo) amenazándole con infligirle un daño extremadamente grave. O se le ha amenazado con matarle, pudiendo haberse utilizado armas (cuchillos, escopetas, etc.) para ello. Las amenazas se han producido de forma premeditada o en una situación de pérdida total de control por parte de los padres. No se ha producido ningún daño ni lesión física, pero esta situación ha provocado en el niño un miedo intenso. Se valora posible que tales amenazas puedan repetirse o materializarse.

2. Gravedad elevada

- Amenaza verbal directa de daño físico grave, sin daño real: En varias ocasiones ha habido amenazas verbales directas y específicas de maltrato o daño hacia el niño. Las amenazas incluyen acciones que, si se llevaran a cabo, le provocarían un daño físico importante (p.ej., amenazas de maltrato físico grave, de deprivación excesivamente prolongada de agua o comida). Las amenazas se han producido de forma premeditada o en una situación de pérdida total de control por parte de los padres. No se ha producido ningún daño ni lesión física, pero esta situación ha provocado en el niño un miedo intenso. Aunque no ha habido ningún intento de llevar a cabo tales amenazas, se valora posible que puedan materializarse.

3. Gravedad moderada

- Amenaza verbal implícita: No ha habido amenazas directas y específicas de maltrato o daño hacia el niño, aunque los padres manifiestan sentirse sobrepasados por él, temen poder hacerle daño, provocar un accidente, etc. (p.ej., padres bajo situaciones de estrés elevado o sobrepasados por la crianza de niños muy pequeños). Esas amenazas indirectas hacen pensar que hay un riesgo de que el niño sufra un daño físico significativo o sea objeto de negligencia. Los padres pueden o no pedir ayuda para evitar materializar sus amenazas.

4. Riesgo leve

- Amenaza verbal implícita sin valoración de que se materialice: No ha habido amenazas directas y específicas de maltrato o daño hacia el niño o las ha habido de forma ocasional, aunque los padres se sienten sobrepasados por él, temen poder hacerle daño, provocar un accidente, etc. Se valora que estas amenazas son manifestación de su frustración y no hay ninguna razón aparente que haga pensar que se van a materializar.

\section{No presente}

- No se han dado amenazas verbales o físicas de maltrato o daño hacia el niño. Las amenazas de castigo corporal de carácter leve no se deben considerar como "amenazas de daño físico".

Manuscrito Recibido: 27/12/2010

Revisión Recibida: 07/02/2011

Manuscrito Aceptado: 08/02/2011 